Thorax, 1980, 35, 653-659

\title{
Hard metal lung disease: importance of cobalt in coolants
}

\author{
INGELA SJÖGREN, GUNNAR HILLERDAL, ANDERS ANDERSSON, AND \\ OLLE ZETTERSTRÖM
}

From Sandvikens Jernverk, Gimo, Sweden and the Department of Pulmonary Diseases, University Hospital, Uppsala, Sweden

\begin{abstract}
Four patients were found to react to occupational exposure to grinding of hard metal (tungsten carbide). Three of the patients had symptoms and signs compatible with an allergic alveolitis, the symptoms disappearing and the chest radiograph clearing when they were absent from work for a few months. Re-exposure to the offending agent led to new signs and symptoms. The first patient was re-exposed twice and each time reacted a little more seriously. After the last episode her chest radiograph has not cleared completely, in contrast to the first two times. The fourth patient had more typical occupational asthma. All the cases occurred in the part of the factory where air concentrations of cobalt were the lowest. The cobalt there is dissolved in the coolant necessary for grinding the hard metal. It occurs mainly in the ionised form, which is known to react with proteins and therefore presumably acts as a hapten. Protective measures, including choosing a coolant with minimal ability to dissolve cobalt and an effective exhaust system, should minimise the risk of this occupational disease in the future.
\end{abstract}

Hard metal lung disease has been described since 1940 as a cause of death in respiratory failure because of fibrosis of the lungs. Hard metal is an alloy consisting of mainly (tungsten) wolfram carbide $(70-95 \%)$ and cobalt $(5-25 \%)$. Various amounts of other metals, such as titanium, tantalum and so on are often added. Because of its hardness, hard metal plays an important and increasing role in the industrialised world. It was first produced in 1926 and after world war 2 production increased substantially. Sweden is, through Sandvik Coromant, one of the world's leading producers of hard metal.

Tungsten carbide has been shown to be inert, and cobalt is considered to be the cause of the damage. $^{1-3}$ A considerable effort has been made over the years in the hard metal industry to reduce the levels of dust and particularly cobalt exposure in the workers' environment. The occurrence of pulmonary disease which could be connected with hard metal exposure in four workers in the present factory was, therefore, unsuspected and alarming. In this report we describe the four

Address for reprint requests: Dr Ingela Sjögren, Department of Thoracic Medicine, Karolinska sjukhuset, S-104 01 Stockholm 60, Sweden. cases and discuss various peculiar factors in connection with them. The amount of various metals in the mediastinal lymph nodes from these patients and from control subjects is also reported.

\section{The industrial process}

The first step in the production is forming wolfram carbide (WC) from the ore. The WC is then milled to a fine powder and mixed with finely milled metallic cobalt. The purity of the powder is very important, and the size of the granules is ideally $1-2 \mathrm{~mm}$. Next, the mixed powder is pressed into the roughly desired shapes and heated under pressure to about $1000^{\circ} \mathrm{C}$. This gives the material enough hardness to be ground more finely for holes to be drilled into it. This is done by dry grinding. Thereafter the product is heated to about $1500^{\circ} \mathrm{C}$, which is above the melting point for cobalt. Finally, the pieces are ground to very exact shapes. Since the material is very hard, only diamond grinders can be used, and cooling is necessary. Pure water cannot be used for various reasons, and different emulsions in water therefore have to be used. The compositions of various coolants are industrial secrets. The final product 
consists of small pieces of metal which are very hard and durable and are used mainly in various tools for the cutting edge.

Since 1969, the Swedish TLV for cobalt has been $0.1 \mathrm{mg} / \mathrm{m}^{3}$. This value was of ten exceeded in the early 1970s, but since then this has only happened rarely. The dustiest part is the mixing area, followed by the dry grinding area where the values generally are lower. In the wet grinding area the values have been consistently very lowfrom unmeasurable quantities to at most $0.01 \mathrm{mg} /$ $\mathrm{m}^{3}$. As a rule, the values have been from 0.002 to $0 \cdot 004$.

Separate investigations of the coolants by the Swedish Board for the Safety of Workers, ${ }^{4}$ and the Local Safety Engineer of the Factory, ${ }^{5}$ show that there is a tendency for the coolants to dissolve and accumulate cobalt, the amount varying a little between different compositions of the coolant. The coolant forms a fine spray of droplets which can be inhaled or deposited on the workers' skin or both. The cobalt in the coolant is mainly in the dissolved or ionised form, and after a few weeks the concentrations of cobalt had increased in some coolants up to $200 \mu \mathrm{g} / \mathrm{g}$. The main difference between the "dry" and the "wet" is thus that the cobalt level is higher in the dry area but it is non-ionised, while in the wet area, the level is very low and the cobalt is in the ionised form. ${ }^{4}$

\section{Case reports}

Four patients, two men and two women, were discovered to have pulmonary disease which could be connected with hard metal exposure during 1968 74. All four were working in the wet grinding area of Sandvikens Jernverk, Gimo. The period of exposure varied between two and four years (fig 1). The investigations were carried out at the Department of Pulmonary Diseases of the University Hospital, Uppsala, with technical help from the Department of Clinical Physiology and Clinical Chemistry.

\section{CASE 1}

This previously healthy woman, born in 1916, had never smoked. There was no history of allergy in the patient or her relatives. In 1966, she started working in the factory in the wet grinding area. In 1968, she developed a dry cough and dyspnoea, particularly on exercise. On a chest radiograph bilateral very small infiltrates were noted. On admission to the hospital she had an intense dry cough, but no crackles could be heard over the lungs. To exclude sarcoidosis, a mediastinoscopy

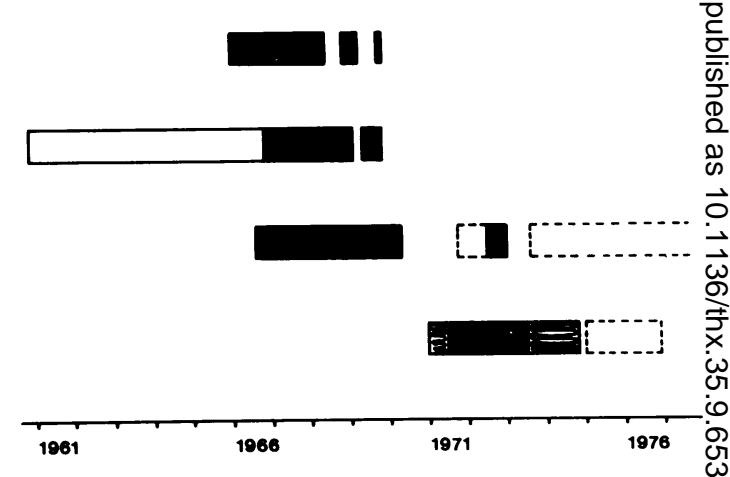

Fig 1 Occupational history: expo:ure through work in the wet grinding area is shown in black, open bars represent work in other parts of the factory in contact $\overrightarrow{c s}$ with hard metal, dashed bars represent work in areas with no contact with hard metal, semi-filled bars represent work with good exhaust facilities. Patients number 1, 2, 3, and 4 from top to bottom.

was performed. No treatment was given. After $\stackrel{\infty}{P}$ few months away from work the patient felס completely healthy and the chest film was alsce normal. She returned to work. After a while he symptoms returned and once again she had to stop working and was reinvestigated in hospital ${ }_{\Omega}^{\mathbb{Q}}$ This time, bilateral crackles were audible and the minimal basal infiltrates had returned on the chess film. After another few months of sick leave she recovered completely again and returned to work? only to have recurrence of the signs and symptom within a month. This time, she had a short course of corticosteroid treatment. She has not returnee to work since then. Her symptoms have slowly diso appeared and her chest films returned to norma after several years. Her lung function tests showe@ variations that closely followed her symptoms and radiographic changes (fig 2 ).

CASE 2

This previously healthy man, born in 1904, had never smoked and had no history of atopy. He started working in the factory in 1961 in the dros area, and from 1966 in the wet grinding area (figs 1). Because of an increasing dry cough and breatho lessness a chest radiograph was taken in 19690 showing bilateral small infiltrates. On auscultation fine crackles could be heard. A bronchoscopy an ${ }^{\circ}$ a mediastinoscopy were performed to exclude sar $=0$ coidosis. All investigations revealed normal find? ings except the chest radiograph and the lun\& function tests. The patient felt better and after few months returned to work where he promptly got worse again. This time he was treated with 


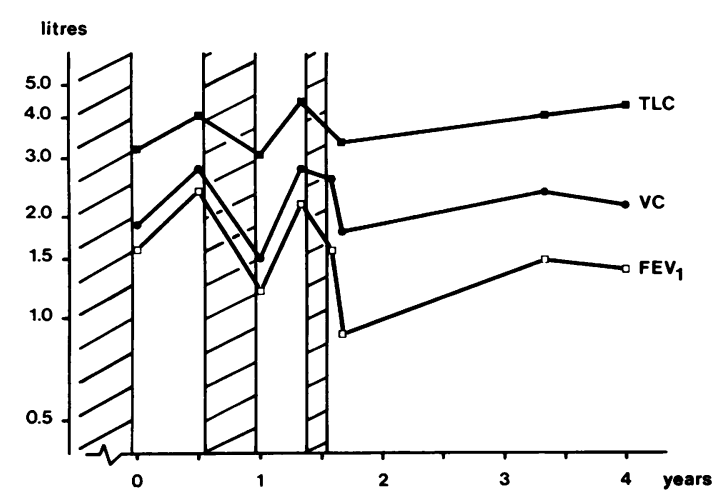

Fig 2 Patient 1: variations in total lung capacity (TLC), vital capacity $(V C)$, and forced expiratory volume during the first second $\left(F E V_{1}\right)$ in relation to periods of exposure, represented by striped areas.

corticosteroids for a short while, and slowly improved. He did not return to work but retired on an old age pension. $\mathrm{He}$ is still regularly checked at the hospital. At the latest visit he felt well with only very slight symptoms, but the chest film still showed minimal changes and crackles could still be heard in the lungs.

\section{CASE 3}

This previously healthy woman, born in 1916, had never smoked. There was no allergy known in the family. She started working in the factory in the grinding area in 1966, but had no symptoms until she came down with "flu" in late 1969 and after that suffered from continuous dry cough and dyspnoea. She was on sick leave from late summer 1970 , and was first seen in the hospital in September 1970 when she was already much better. Bilateral crackles were heard and the chest film showed bilateral mottling. She was investigated as the other patients and since she gradually recovered, no treatment was given. After more than half a year of sick leave she returned to the factory, initially to a dry part where she suffered no symptoms, and then to the wet grinding area again. Very soon her symptoms returned and she had to be treated with corticosteroids. After recovery she has been working in a part of the factory where she is not exposed to hard metal dust. She has since remained symptomless, but her radiograph has remained abnormal with small bilateral densities without any tendency to progression.

CASE 4

This man, born in 1912, stopped smoking in 1955 . There was no family history of atopy and he had been previously healthy apart from slightly raised blood pressure, treated with diazides from 1972. In 1971 he started to work in the wet grinding area of the factory and began to have asthmatic attacks on weekdays, starting Monday afternoon and evening, with remissions during weekends and holidays. The symptoms occurred only during a period of two years when he was working at a machine which lacked proper exhaust facilities. He was investigated at a time when these symptoms had subsided. The chest radiograph showed an infiltrate in the right upper lobe which may have been caused by tuberculosis or localised fibrosis. There were also small infiltrates in the left upper lobe. There were no crackles in the lungs. Inhalation of dust from the factory caused a slow but marked reduction in peak expiratory flow rate (fig 3). Peak expiratory flow rate measures during one work day even at the time when he had no overt symptoms were markedly lower (around 350 1) throughout the day than his habitual levels at the clinic or in hospital (around 450 1). The patient was moved to an area where he was not exposed to hard metal dust and remained there until retirement practically symptom-free. At the latest check-up in the lung clinic, he was symptomfree, but still had slight bilateral changes on his chest radiographs.

Bronchoscopy was performed on all four patients and was normal in all cases. All four had also a mediastinoscopy mainly to exclude sarcoidosis because of the reticular changes on the radiographs. Glands from the mediastinum of these patients as well as from four control subjects, who worked in the same factory but did not have evidence of hard metal lung disease and two unexposed control subjects, were analysed by spectrophotometric analysis at AB Atomenergi, Studsvik, Sweden according to the method described by Brune and collaborators. ${ }^{6}$ The results of these analyses are shown in table 1 . The control glands in this investigation were taken from patients who, for various reasons, mainly suspicion of carcinoma, had undergone mediastinoscopy. The lymph nodes from the patients and the control subjects were all histologically normal, showing only varying degrees of anthracosis. All of the patients were non-smokers or ex-smokers, in contrast to the control subjects who were all smokers.

All four patients had contact eczema, which developed within a few months of starting to work in the wet grinding area. Patch tests were positive to cobalt in all four patients, with eczematous lesions developing within a few days after cobalt had been applied to the skin. 


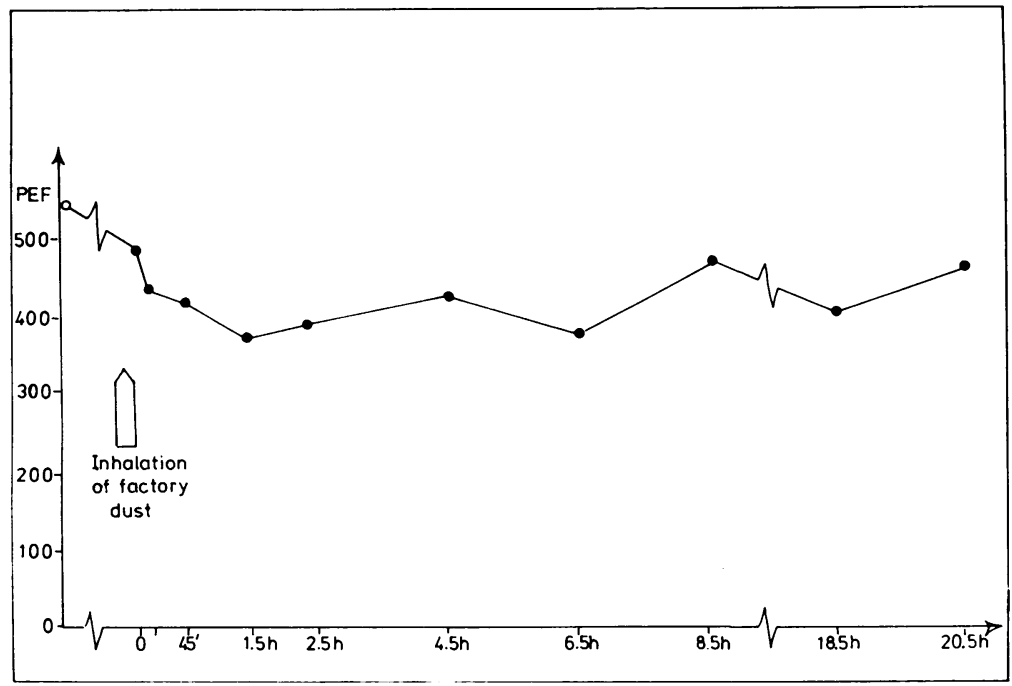

Fig 3 Patient 4: variations in peak expiratory flow (PEF) after inhalation of dust from the factory.

Table 1 Quantities of tungsten $(W)$, tantalum $(T a)$, and cobalt $(C o)$ in mediastinal lymph-nodes $(\mu g / g$ dry weight) determined by spectrophotometric analysis from patients with hard metal lung disease and from control subjects without hard metal lung disease with or without exposure to hard metal dust. Smoking habits are also indicated $(N S=$ non-smoker, $S=$ smoker, $X S=e x$-smoker)

\begin{tabular}{|c|c|c|c|c|c|c|c|c|}
\hline \multirow[t]{2}{*}{ Patients } & & \multirow[t]{2}{*}{ Sex } & \multirow[t]{2}{*}{$\begin{array}{l}\text { Skin allergy } \\
\text { to cobalt }\end{array}$} & \multirow[t]{2}{*}{$\begin{array}{l}\text { Years of } \\
\text { exposure }\end{array}$} & \multirow[t]{2}{*}{$\begin{array}{l}\text { Smoking } \\
\text { habits }\end{array}$} & \multicolumn{3}{|c|}{$\begin{array}{l}\text { Amount of metal in mediastinal } \\
\text { lymph-nodes }(\mu \mathrm{g} / \mathrm{g} d r y \text { weight })\end{array}$} \\
\hline & & & & & & $W$ & $\mathrm{Ta}$ & Co \\
\hline 1 & EJ & $\mathbf{F}$ & + & 3 & NS & $6 \cdot 7$ & $<3$ & $<1 \cdot 2$ \\
\hline 2 & HF & $\mathbf{M}$ & + & 3 & NS & 34 & $6 \cdot 1$ & $3 \cdot 1$ \\
\hline 3 & $\mathbf{M M}$ & $\mathbf{F}$ & + & 4 & NS & $15 \cdot 3$ & $<3$ & $<1 \cdot 2$ \\
\hline 4 & ML & $\mathbf{M}$ & + & 3 & $\mathbf{X S}$ & 380 & 36 & 7 \\
\hline \multicolumn{9}{|c|}{ Exposed control subjects } \\
\hline 1 & $\mathbf{Y P}$ & $\mathbf{M}$ & - & 23 & $\mathbf{S}$ & 2 & $<3$ & $<1 \cdot 2$ \\
\hline 2 & GK & $\mathbf{M}$ & - & 20 & $\mathbf{S}$ & $7 \cdot 2$ & $<3$ & $<1 \cdot 2$ \\
\hline 3 & TL & $\mathbf{F}$ & + & 7 & $\mathbf{S}$ & $8 \cdot \overline{9}$ & $<3$ & $<1 \cdot 2$ \\
\hline 4 & HE & $\mathbf{F}$ & - & 2 & $\mathbf{S}$ & $<2$ & $<3$ & $<1 \cdot 2$ \\
\hline \multicolumn{9}{|c|}{ Non-exposed control subjects } \\
\hline 1 & HJ & $\mathbf{M}$ & not tested & 0 & $\mathbf{S}$ & & $<3$ & $<1 \cdot 2$ \\
\hline 2 & LS & $\mathbf{M}$ & not tested & 0 & $\mathbf{S}$ & $<2$ & $<3$ & $<1 \cdot 2$ \\
\hline
\end{tabular}

Lung function studies were done in all patients. Variations can be seen, closely following the degree of exposure (fig 2, table 2) Duco was decreased in 1968 in patient 1 , but had returned to normal in 1972 when she was no longer exposed.

\section{Discussion}

Hard metal lung disease was first described in 1940. Since then several other reports have followed. Earlier the disease occurred mainly in the mixing or forming areas of the factories, since these were the areas entailing the greatest risk of exposure to metal dust. Mostly the earlier reports describe a severe progressive fibrosis of the lungs in persons occupied in this type of work..$^{-9}$ Con siderable evidence suggests that cobalt is the. offending component. ${ }^{1011}$ It is now well acceptefo that hard metal lung disease can cccur in twp forms: an interstitial lung disease with all the classical signs of pulmonary fibrosis and an ob structive airways syndrome. ${ }^{13}$ We suggest that both these seemingly different reactions actual occur through immunological mechanisms, an that they might be two variants of the same disease.

The ionised form of cobalt reacts readily wit⿱艹 proteins $^{12}$ and can therefore presumably act as hapten. This seems to us to be the most probabR explanation for the fact that the cases of lures 
Table 2 Variations in physiological findings in patients 1-4 with time. Values obtained shortly after exposure are in italics

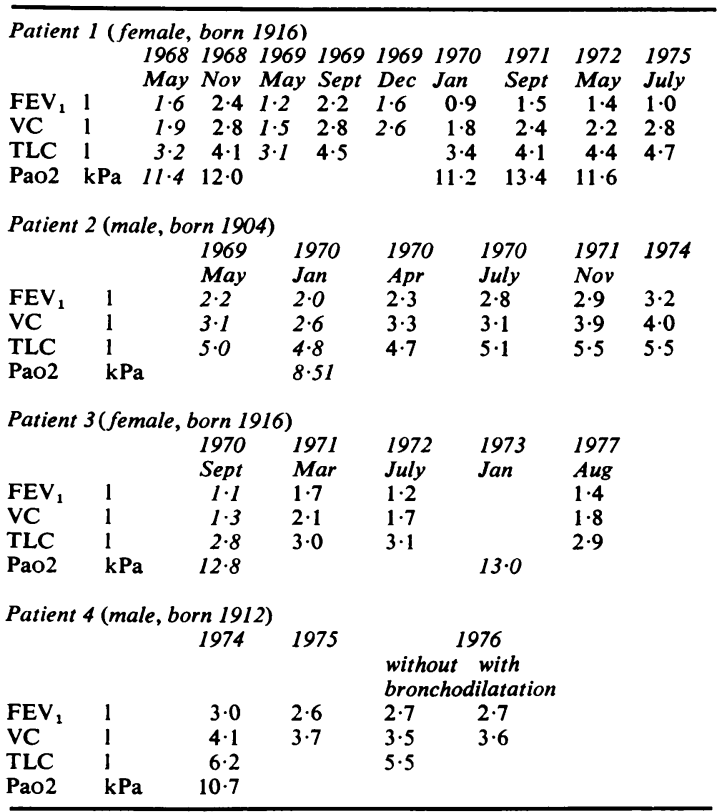

disease all occurred at the wet grinding area of the factory, even though the concentrations of cobalt in the air are the lowest there.

The present factory is one of the two main factories in Sweden. It started producing hard metal in 1951. Today approximately $1500 \mathrm{em}-$ ployees are working with this product. During these years more than 3000 people have been working directly with hard metal. The incidence of lung disease, as judged from the four cases presented here, is thus low. There might of course have been cases who stopped work because of symptoms, but this is probably not very common. Gimo is a small place and other jobs are hard to find. There have been regular surveys of the workers with chest radiographs every second to third year during the last decade, so any cases of interstitial fibrosis should have been discovered. However, non-specific irritation of the airways is a fairly common finding in the factory, as shown by Alexandersson. ${ }^{13}$

Cobalt occurs endogenously in the human body in cobalamine. Cobalt has been used for treatment of anaemia, since one of its toxic effects is to induce polycythaemia. No polycythaemia was observed in any of our cases. Cobalt is readily dissolved in body fluids, and previous investigators have not been able to detect any amount of cobalt in the lung tissue or glandular tissue. ${ }^{1114}$ In the present investigation, however, the amounts of metals detected in the glands of patients with hard metal disease tended to be higher than in control subjects doing the same kind of work, even if the latter had worked much longer in the industry (table 1). This might indicate a greater absorption of metals in the patients because of inflammation of the mucosa or longer retention in the lymph nodes of the patients. Tungsten has been shown to be inert ${ }^{15}$ so the higher content of this metal only indicates a higher absorption. Since cobalt is readily dissolved in body fluids it is of some interest to observe increased amounts of this metal in some of the patients, but in none of the control subjects although these were all smokers. It is possible that some people have a higher tendency to absorb certain substances through their epithelium and have a much higher risk of developing adverse reactions to these agents because their immunological system receives a much higher dosage of them-but this, of course, remains highly speculative. However, further investigations of this aspect are probably worth while. The main problem is finding patients, who seem to be very rare, and also control subjects where mediastinoscopy is clinically justified.

The interstitial lung disease seen in three of our patients was characterised by a relatively acute onset, and has features that also in other respects are consistent with an allergic alveolitis. Cobalt is a well-known skin sensitiser inducing contact eczema. All our patients had contact eczema, and they had positive patch tests to cobalt. It seems probable that the ionised cobalt, which can react with proteins, is the allergenic substance inducing disease in the lung as well as in the skin, probably acting as a hapten after having been coupled to some protein in the body. Allergic contact sensitivity can be elicited apart from in the skin also in mucous membranes, and sensitised lymph nodes seem to play an important role. ${ }^{16}$ Whether the present condition represents a true allergic alveolitis or an allergic contact sensitivity in the mucous membranes of the bronchi is a matter for speculation.

None of our patients were smokers. In fact, in a recent study by Warren, ${ }^{17}$ it was found that extrinsic allergic alveolitis seemed to be significantly correlated with non-smoking in Winnipeg as well as in most reports where smoking habits were recorded.

It seems probable that the hard metal lung disease in our cases started as an allergic alveolitis, 
which can progress to severe fibrosis if the exposure is not stopped. In patient 1 the reversibilty of the reduced lung function was less after each exposure. It must, therefore, be important to terminate exposure immediately suspicion of hard metal lung disease occurs. Since dermatological symptoms seem to precede lung symptoms it is wise to remove from exposure all who show such symptoms and have a cutaneous patch test showing sensitivity to cobalt.

Contamination of the coolants with microorganisms, fungi, or protozoa seems unlikely as the coolants are periodically cleaned and changed; nor were any gross signs of such contamination present. We do not believe that the symptoms were caused by a variation of "humidifier fever."18-20 With a known allergen already shown to have sensitised the patient, this seems to us to be the most plausible cause of the disease. This is further strengthened by the investigations of Coates et al, ${ }^{21}$ who in a tungsten carbide manufacturing plant found nine patients with a respiratory sensitisation syndrome, and where tests showed cobalt to be the offending substance. Similarly, Bruckner ${ }^{22}$ has described a case with recurring asthma when he worked with grinding of tungsten carbide-tipped tools and where no other agents could be found to give symptoms.

The findings in the present patients led to an increased awareness about the possible harmful effects of cobalt exposure under present conditions in the Swedish hard metal industry. An epidemiological study of workers in the hard metal industry has shown that irritation of the respiratory passages is a common complaint in exposed workers and that the symptoms are mainly obstructive, but that a chronic reduction in the pulmonary function cannot be excluded. This kind of response was more common in smokers than in non-smokers. However, workers who had been removed from exposure because of complaints were not included. ${ }^{13}$

There has also been extensive testing of coolants to find one which has the least tendency to dissolve the cobalt, and promising results in these aspects seem to have been reached at the factory. Likewise, there has now been much improvement in the ventilation and every machine has an exhaust system to minimise the workers' exposure. It is hoped that these measures will prevent the appearance of further cases. However, since allergenic mechanisms are involved, even very minute exposures may sensitise certain individuals. So far, since our last case was diagnosed in 1973, no new cases have occurred.

\section{References}

1 Parkes WR. Occupational lung disorders. Londo Butterworth 1974:478-82.

2 Reichel G. Hartmetallibrose. In: Ulmer Wfor Reichel G (eds). Handbuch der inneren Medizi funfte Auflage, Band 4, Atmungsorgane 1. Tet: Pneumokoniosen. Berlin: Springer Verlag, 1976: 481-3.

3 Morgan WKC, Seaton A. Occupational lung diseases. Philadelphia, London, Toronto: W Saunders, 1975:244-7.

4 Einarsson ö, Lindstedt G, Wahlberg J. Förekom av allergena metaller (krom, kobolt, nickel) $\dot{d}$ oljeemulsioner i vissa verktygs-maskiner. (Occuf్̂ rence of allergenic metals (chrome, cobalt, nickeß in oil emulsions in certain tool machines). Investigation Report, Arbetarskyddsstyrelsen 1974 AMK 002/74.

5 Eriksson E. Skyddstekniska synpunkter på skä윯 vätska (technical protective points regarding $\mathrm{cooB}$ ants). Internal report, Sandvik AB, Gimo 1977. D

6 Brune D, Bivered B, Mattson S, Zetterström $\mathrm{O}_{\text {. }}$ Neutron activation analysis as a diagnostic too for detecting lung disease initiated by hard-metạ dust. In: Nuclear activation techniques in the life sciences. Vienna: International Atomic Energes Agency, 1972:213-8.

7 Lundgren KD, Öhman H. Pneumokoniose in de Hartmetallindustrie. Teknische und Medizinisch Untersuchungen. Virchows Archiv 1954; 3250 259-84.

8 Miller CW, Davis MW, Goldman A, Wyatt JP오ำ Pneumoconiosis in the tungsten-carbide tool in dustry. Report of three cases. Arch Industr Hy $1953 ; 8: 453-65$.

9 Reber E, Burckhardt P. Über Hartmetallstau blungen in der Schweiz. Respiration 1970; 27 $120-53$.

10 Coates EO, Watson JHL. Diffuse interstitia홈 lung disease in tungsten carbide workers. $A n \bar{m}$. Intern Med 1971; 75:709-16.

11 Harding HE. Notes on the toxicology of cobalk metal. B J Ind Med 1950; 7:76-8.

12 Hellsten E, Blomberg M, Henrikson-Enflo A Sundbom M, Vokal H. Kobalt (Cobalt). Stock음 holm: University of Stockholm, Institute of Physics, 1976: Report 76.

13 Alexandersson R. Undersökningar över effekter̃ av exposition för kobolt. VI. Exposition, upptagu och lungpåverkan av kobolt i hard-metallingdustri. Arbete och Hälsa (Vetenskaplig skriftserie) Stockholm: Arbetarskyddsverket, 1979.

14 Bech AO, Kipling MD, Heather JC. Hard meta底 disease. Br J Ind Med 1962; 19:239-52.

15 Schepers GWH. The biological action of tungstent and carbon. Arch Ind Health 1955; 12:140-6.

16 Baer RL, Harber LC. Allergic excematous con $-\mathbb{D}$ tact dermatitis. In: Samter Max (ed). Immunological diseases. Second edition. Boston: Little,, Brown and Company, 1971:936-43. 
17 Warren CPW. Extrinsic allergic alveolitis: a disease commoner in non-smokers. Thorax 1977; 32:567-9.

18 Edwards JH, Griffiths AJ, Mullins J. Protozoa as sources of antigen in "humidifier fever". Nature 1976; 264:438-9.

19 Friend JAR, Gaddie J, Palmer KNV, Pickering CAC, Pepys J. Extrinsic allergic alveolitis and contaminated cooling-water in a factory machine. Lancet 1977; 1:297-300.

20 Editorial. Inhalation fevers. Lancet 1978; 1:249-50.

21 Coates EO, Sawyer HJ, Rebuck JW, Kvale PA, Sweet LW. Hypersensitivity bronchitis in tungsten carbide workers. Chest 1973; 64:390.

22 Bruckner HC. Extrinsic asthma in a tungsten carbide worker. J Occup Med 1967; 9:518-9. 